\section{SEM Image Sharpness Analysis}

M.T. Postek ${ }^{*}$ and A.E. Vladar**

*NIST, Gaithersburgh MD, **Hewlett-Packard

ULSI Research Laboratores, Palo Alto, CA.

Fully automated or semi-automated scanning electron microscopes (SEM) are now commonly used in semiconductor production and other forms of manufacturing. The industry requires that an automated instrument must be routinely capable of $5 \mathrm{~nm}$ resolution (or better) at $1.0 \mathrm{kV}$ accelerating voltage for the measurement of nominal $0.25-0.35$ micrometer semiconductor critical dimensions. Testing and proving that the instrument is performing at this level on a day-by-day basis is an industry need and concern which has been the object of a study at NIST. The fundamentals and results are discussed in this paper.

In scanning electron microscopy, two of the most important instrument parameters are the size and shape of the primary electron beam and any image taken in a scanning electron microscope is the result of the sample and electron probe interaction. The low frequency changes in the video signal, collected from the sample, contain information about the larger features and the high frequency changes carry information of finer details. The sharper the image, the larger the number of high frequency components making up that image. Fast Fourier Transform (FFT) analysis of an SEM image can be employed to provide qualitative and ultimately quantitative information regarding the SEM image quality.

Figure 1a is a micrograph of a heavily gold coated zinc oxide powder viewed at $1.5 \mathrm{keV}$. The image appears unsharp due to SEM performance and induced astigmatism. Figure $1 \mathrm{~b}$ is a much sharper micrograph at 1.0 $\mathrm{keV}$ on that same sample. Figure $1 \mathrm{c}$ is a high accelerating voltage image. It is apparent that the sharpness of the image improves from Figure 1a through 1c. The FFT power spectra of the images are shown in Figures $1 \mathrm{~d}$, $e$ and $f$, respectively. The high frequency information increases as the image gets sharper and the center part of the power spectra gets broader

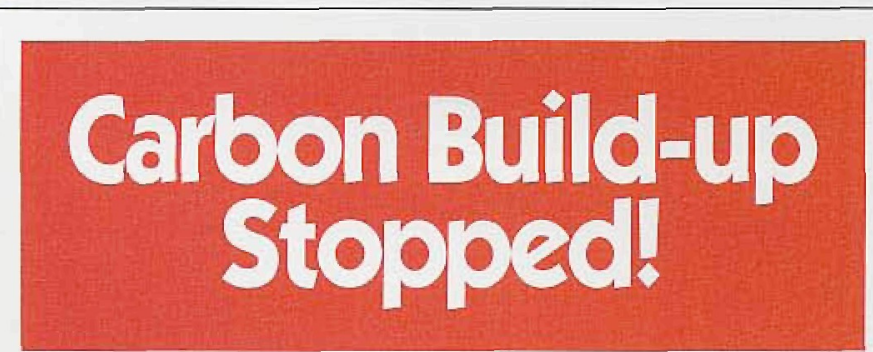

\section{SEM Laboratory Secret Revealed:}
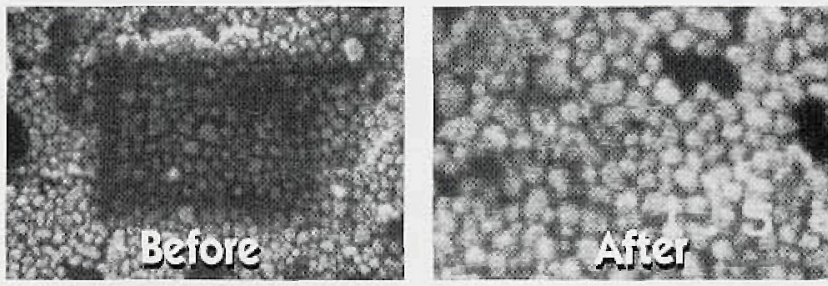

SEM manufacturers won't admit it, but most SEMs are subject to contamination build-up-even dry pumped systems. To stop hydrocarbon condensation, smart SEM users rely on the XEI Scientific SEM-CLEAN ${ }^{T M}$ system.

Result: Outstanding pictures at low $\mathrm{kV}$ and high resolution and no ol on EDS X-ray detector windows. The Nitrogen purge of the inexpensive SEM-CLEAN system cleans your electron microscope while you're away.

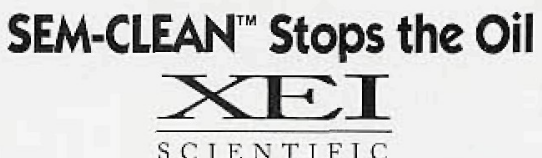

3124 Wessex Way, Redwood City, CA 94061 415-369-0133 Fax 415-363-1659
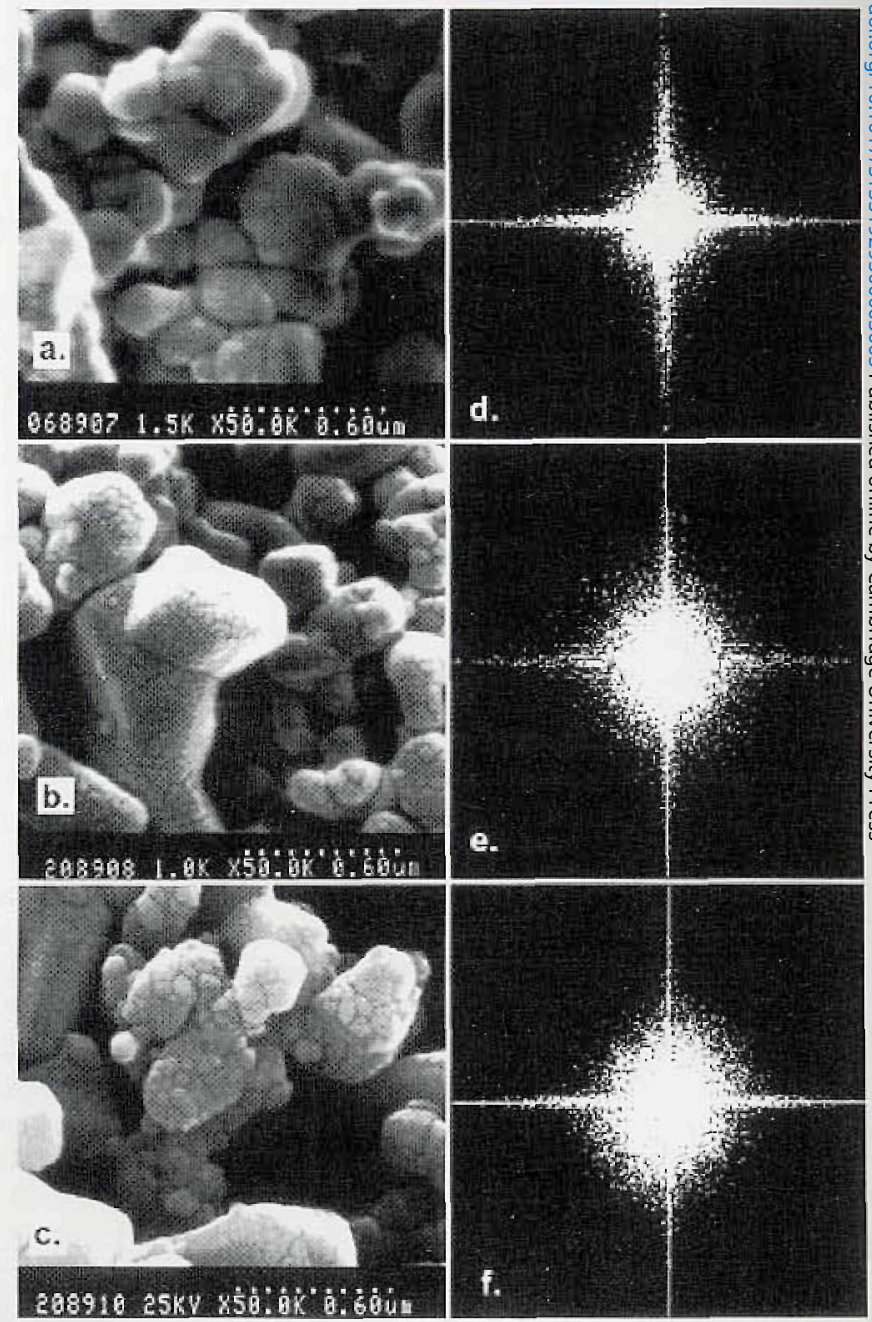

FIG. 1. Image sharpness evaluation. Displayed are three scanning electron micrographs of varying quality and the respective FFT analysis. Note how the high frequency components of the image increase as the image improves in sharpness.

which is clearly shown in Figures $1 d$, e and $\mathrm{f}$. This characteristic can be used in calculations to compute relative sharpness of an image series. Using ISAAC? with the use of a script containing the FFT routine, the frequency domain representation was computed in both $x$ and $y$. With this sampling algorithm, the calculations occurred on the central two third of the images in order to minimize the effect of any possible distortions of the original image. The $x$ and $y$ sums were saved as text files. Further calculations were accomplished with spreadsheet software.

The technique described here, utilizing the sharpness concept, is facilitated by the use of the FFT techniques to analyze the electron micrograph to obtain the evaluation. This is not the first application of Fourier techniques to SEM images ${ }^{3}$ but it is the first integrated approach considering the sample, computer analysis and measurement algorithm. This technique can be used to check and optimize two basic parameters of the primary electron beam, the focus and astigmatism. It also facilitates the periodic resolution determination of the SEM in an objective and quantitative form.

Contribution of the National Institute of Standards and Technology (NIST). This work was supported in part by the National Semiconductor Metrology Program at NIST; not subject to copyright.

2. M.T. Postek and A.E. Vladar, Scanning 18(1996)1-7.

3. T.A. Dodson ands D.C. Joy, Proc. Xllth Int. Cong. for EM. San Francisco Press. (1990)406-407.

Reprinted with permission from Microscopy And Microanalysis 1996 




\section{What does fei. stand for?}

Our compact, UHV, field emission columns are used by researchers world wide. Innovative electrostatic optics and dedicated electronics allow you to integrate a high current density electron or ion column into most vacuum systems. FEI also supplies researchers with other specialized products...

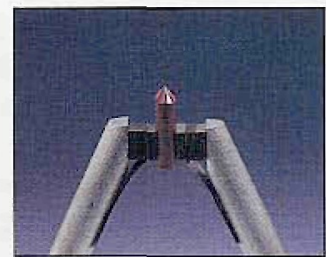

$\mathrm{LaB}_{6}$ an $\mathrm{CeB}_{6}$ Cathodes

FEl's Mini-Vogel Mount, the first universally compatible long-life, high-stability LaB6 cathode, provides excellent performance and the best cost-per-use value for installation into your EM systems.

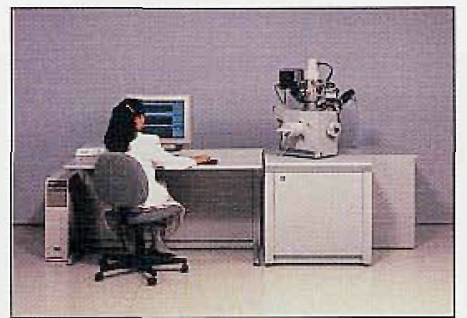

\section{FIB Workstations}

Focused ion beam micromilling workstations range from the 8"-wafer compatible model to the economical $2^{\prime \prime}$ small sample model ideal for semiconductor, biological, TEM, and MEMS specimens.

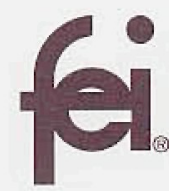

FEl Company

7451 NE Evergreen Parkway

Hillsboro, OR 97124-5830

(503) 640-7500 Fax (503) 640-7509

email:rsk@feico.com

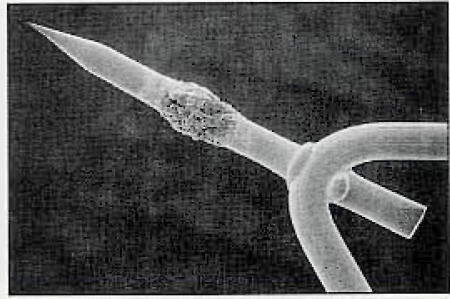

Field Emission Cathodes FEI supplies Scholtky field emitters to EM manufacturers worldwide. Schottky emission's high current intensity has established it as the preferred electron source for high resolution SEM, TEM, Auger, ESCA, $E D X$, and lithography. 